\title{
Development of a SARS Coronavirus Vaccine from Recombinant Spike Protein Plus Delta Inulin Adjuvant
}

\author{
Clifton McPherson, Richard Chubet, Kathy Holtz, Yoshikazu Honda-Okubo, \\ Dale Barnard, Manon Cox, and Nikolai Petrovsky
}

\begin{abstract}
Given periodic outbreaks of fatal human infections caused by coronaviruses, development of an optimal coronavirus vaccine platform capable of rapid production is an ongoing priority. This chapter describes the use of an insect cell expression system for rapid production of a recombinant vaccine against severe acute respiratory syndrome coronavirus (SARS). Detailed methods are presented for expression, purification, and release testing of SARS recombinant spike protein antigen, followed by adjuvant formulation and animal testing. The methods herein described for rapid development of a highly protective SARS vaccine are equally suited to rapid development of vaccines against other fatal human coronavirus infections, e.g., the MERS coronavirus.
\end{abstract}

Key words Coronavirus, SARS, MERS, Vaccine, Adjuvant, Delta inulin, Advax adjuvant, Baculovirus, Manufacture, cGMP

\section{Introduction}

The severe acute respiratory syndrome coronavirus (SARS) was first identified in 2003 after a series of fatal pneumonia cases characterized by an inflammatory cell infiltrate with diffuse alveolar damage [1] started in Hong Kong before spreading to other countries [2]. Before being controlled by quarantine measures, $\sim 8000$ humans were infected, with fatality as high as $50 \%$ in the elderly and an overall case fatality rate of $\sim 10 \%$ [2]. More recently, the Middle East respiratory syndrome coronavirus (MERS) has caused a series of serious and, in some cases, fatal human infections [3]. Given the risk of future serious human coronavirus outbreaks, development of a suitable vaccine platform to protect against such viruses is a major priority. These vaccines present several challenges including the rapidity with which these outbreaks develop and hence the need for rapid vaccine manufacture. Hence, a successful coronavirus vaccine platform must overcome multiple challenges. 
SARS CoV is a positive-stranded RNA virus $29.7 \mathrm{~kb}$ in length with 14 open reading frames [4]. Initial SARS vaccine candidates were produced from inactivated virus. Inactivated whole-virus vaccines provided only modest protection, inducing low-neutralizing antibody titers that did not protect against infection but were associated with faster lung clearance of virus [5]. However, immunization of mice with inactivated vaccines either alone or formulated with alum adjuvant resulted in severe lung eosinophilic pathology in response to virus challenge [6-9], similar to enhanced lung pathology seen with SARS virus reexposure after primary infection [10]. Hence a major challenge when developing a SARS vaccine is to identify strategies to avoid lung eosinophilic pathology.

A further challenge when developing vaccines based on inactivated SARS virus is the need for high-containment biosafety level 3 cGMP manufacturing facilities [11]. This makes vaccine manufacture more complex and expensive and restricts the number of vaccine doses that can be rapidly manufactured. To counter these challenges, it would be preferable to produce a subunit vaccine that just like inactivated virus was able to induce neutralizing antibodies against SARS-CoV, but rather than requiring BSL3 manufacture was able to be produced in a regular recombinant protein manufacturing environment.

The potential solution to this problem lies in the coronavirus spike protein (S protein), which in the case of SARS virus binds to angiotensin-converting enzyme 2 and CD209L and induces receptor-mediated virus endocytosis, thereby being critical to virus entry into target cells $[12,13]$. $S$ protein could thereby provide an ideal antigen with which to induce neutralizing antibodies against SARS virus [14, 15]. However, while immunization with $S$ protein in animal models provided some protection against SARS virus $[16,17], S$ protein-immunized animals when subsequently challenged with live virus developed severe lung eosinophilic immunopathology, with this problem exacerbated even further when $S$ protein vaccine was formulated with alum adjuvant $[6,9]$. A similar problem of lung eosinophilic immunopathology has been seen with other viruses including respiratory syncytial virus (RSV) vaccines, which prime for an excessive and harmful Th2-dominated lung immune response upon subsequent virus exposure [18]. Lung eosinophilic immunopathology is exacerbated by formulation of such vaccines with any adjuvant that induces excess Th2 immune polarization, e.g., aluminum salt adjuvants [6, 9]. Hence, while $S$ protein would appear to be an ideal SARS vaccine antigen, there is first the need to reduce the risk of lung eosinophilic immunopathology being induced by the vaccine.

Described below are methods used for the development and manufacture of a recombinant subunit vaccine based on an $S$ protein antigen lacking transmembrane and cytoplasmic domains ( $S$ $\Delta \mathrm{TM}$ ) that was expressed using a baculovirus insect cell expression 
platform. As the $S \Delta \mathrm{TM}$ protein antigen itself has low immunogenicity $[16,17]$, steps are also described for formulation with a safe and effective adjuvant [19]. As aluminum adjuvants are contraindicated for SARS vaccines given they may exacerbate lung eosinophilic pathology; instead methods are described for formulation of the $\mathrm{S} \Delta \mathrm{TM}$ protein with $\operatorname{Advax}^{\mathrm{TM}}$, a safe and effective adjuvant based on delta inulin $[20,21]$ that has been previously shown in animal models to enhance the immunogenicity of a broad range of viral and bacterial antigens [22-30] and has also been shown safe and effective in preliminary human clinical trials [31, 32]. Notably, Advax adjuvant was recently shown to enhance the immunogenicity and protection conferred by both inactivated and recombinant SARS vaccines, without the excess Th2 bias of alum adjuvants and hence without the risk of inducing lung eosinophilic immunopathology [33].

For this project a recombinant baculovirus was designed to express the ectodomain of the SARS S protein, lacking the transmembrane and cytoplasmic domains [17]. The recombinant protein expressed by this vector was termed SARS $S \Delta T M$. This truncated version of the $S$ protein was selected as it contains the receptor-binding domain (RBD) and was able to be expressed in insect cells at a higher level than the full-length membrane-bound version. The SARS S RBD has been shown to induce neutralizing antibodies against the SARS CoV $[14,15]$. After infection of expres $\mathrm{SF}+{ }^{\circledR}$ insect cells with the recombinant baculovirus, the $\mathrm{S}$ $\Delta \mathrm{TM}$ protein is expressed and secreted into the cell culture medium [17]. The procedure detailed below for purifying the SARS S $\Delta T M$ protein can be followed after production of the protein in a baculovirus/insect cell system. The process is designed for a $45 \mathrm{~L}$ fermentation in a $60 \mathrm{~L}$ bioreactor but may be adjusted to other scales as necessary. Following harvest, the SARS S $\Delta$ TM protein is purified by column chromatography; a schematic is provided in Fig. 1 . In the first step, the supernatant is flowed through linked UNOsphere $S$ (UNO S) and DEAE sepharose columns. DNA and protein impurities are removed, and the SARS $S \Delta T M$ protein remains in the flow through. The flow through from the UNO S/ DEAE step is applied to lentil lectin sepharose, SARS S $\Delta T M$ binds, and impurities are removed. Following elution from the lentil lectin sepharose column, the protein is concentrated, and buffer is exchanged by ultrafiltration. The retentate from the ultrafiltration step is processed through a $0.22 \mu \mathrm{m}$ filter, and the purified protein is stored at $-20{ }^{\circ} \mathrm{C}$. Prior to intended use, the purified SARS $S \Delta T M$ protein is mixed under conditions with a suspension of Advax ${ }^{\mathrm{TM}}$ delta inulin adjuvant particles and either aseptically filled into single-dose vials or loaded directly into syringes ready for vaccination. Lastly, the adjuvanted SARS vaccine is tested for efficacy and safety in animal immunogenicity and SARS challenge models. 


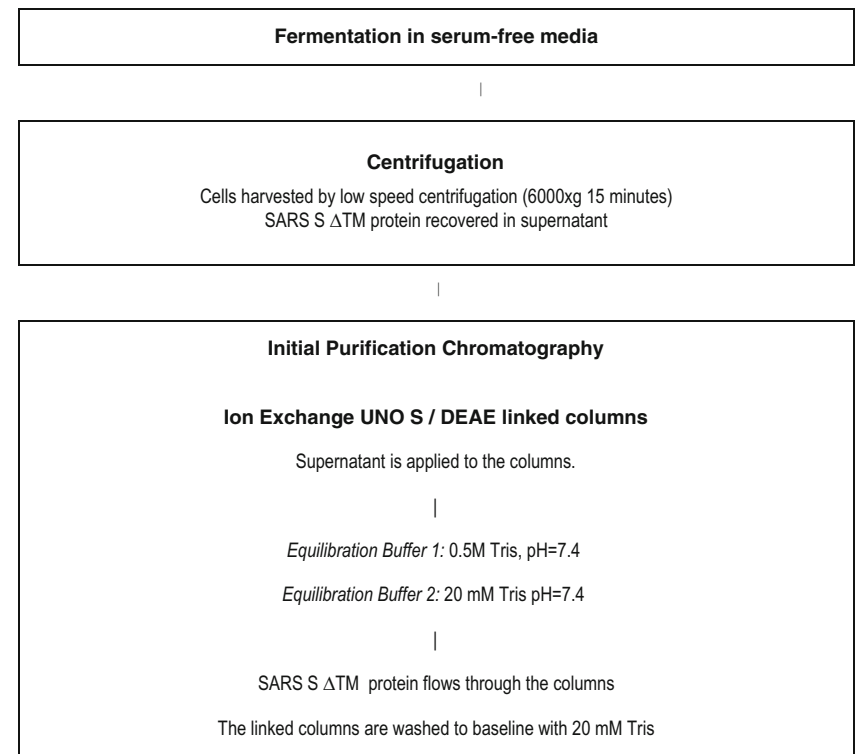

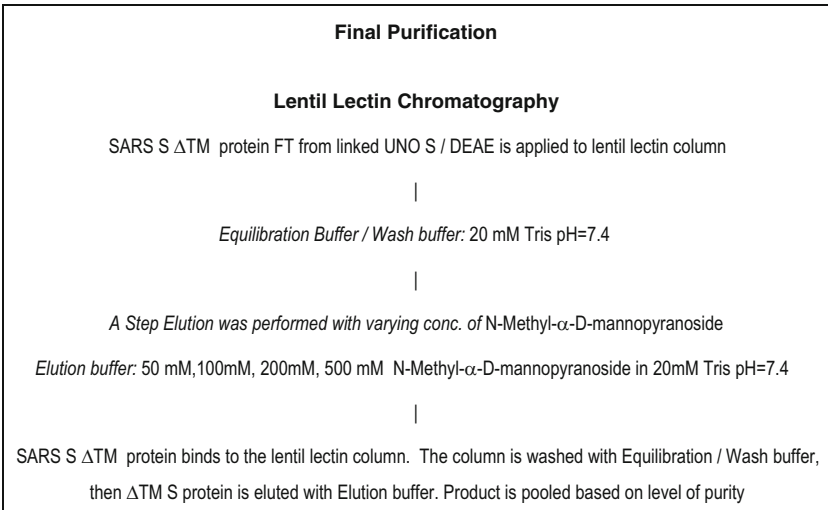

Pellet discarded

Cellular material removed

Contaminants discarded

Additional viral clearance

DNA and protein impurities

reduced

Protein impurities removed

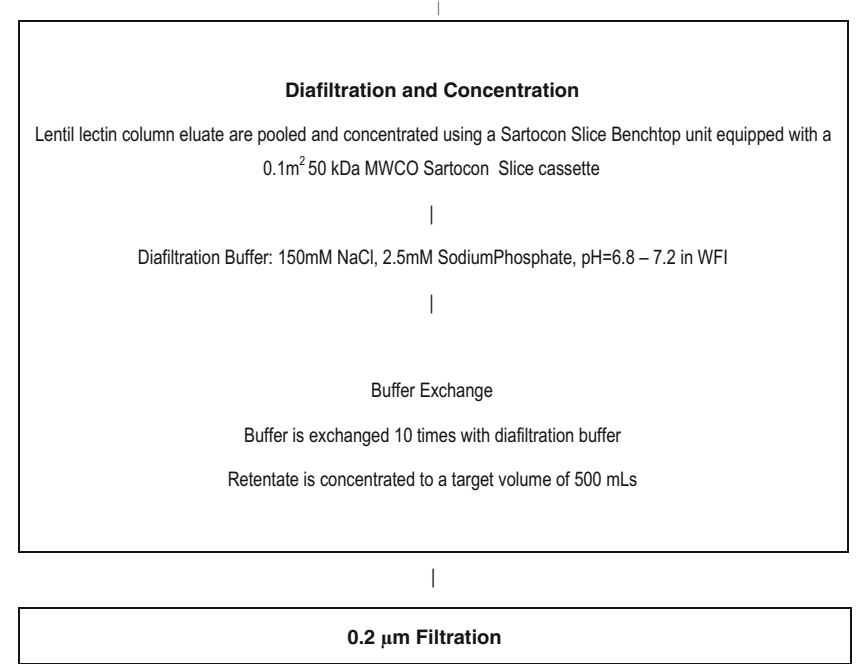

Protein is concentrated and buffer is exchanged

Small protein contaminants (smaller than about $50 \mathrm{kDa}$ ) are removed in the filtrate

Fig. 1 Process flow diagram of SARS $S \triangle T M$ protein 


\section{Materials}

\subsection{Fermentation} Harvest

2.2 UNO S/DEAE

Column

Chromatography

\subsection{Lentil Lectin Capture Chromatography}

2.4 Concentration, Ultrafiltration, and $0.22 \mu \mathrm{m}$ Filtration
1. 1 L Nalgene centrifuge bottles (Thermo Scientific).

2. High-speed centrifuge.

3. Centrifuge rotor to accommodate $1 \mathrm{~L}$ bottles.

4. Sterile $50 \mathrm{~L}$ Nalgene carboy (Thermo Scientific).

5. $0.22 \mu \mathrm{m}$ filter (EMD Millipore).

1. Two BPG columns (GE Healthcare).

2. UNOsphere S chromatography resin (Bio-Rad).

3. DEAE Sepharose Fast Flow chromatography resin (GE Healthcare).

4. Chromatography system equipped with UV and conductivity monitors.

5. Tris(hydroxymethyl)aminomethane (Trizma; Sigma-Aldrich).

6. Concentrated $\mathrm{HCl}$.

7. Purified water.

8. Sterile 50 L Nalgene carboy (Thermo Scientific).

1. XK 50 column (GE Healthcare).

2. Lentil lectin Sepharose 4B (GE Healthcare).

3. Chromatography system equipped with UV and conductivity monitors.

4. Tris(hydroxymethyl)aminomethane (Sigma-Aldrich).

5. Concentrated $\mathrm{HCl}$.

6. Purified water.

7. N-methyl- $\alpha$-D-mannopyranoside (Sigma-Aldrich).

8. Sterile Nalgene square $250 \mathrm{~mL}$ polycarbonate bottles (Thermo Scientific).

1. Sartocon Slice 200 bench top system (Sartorius).

2. Sartocon Slice 200 PESU cassette (Sartorius).

3. Pump.

4. Sodium phosphate monobasic monohydrate (Sigma-Aldrich).

5. Sodium phosphate dibasic 12-hydrate (Sigma-Aldrich).

6. Sodium chloride (Sigma-Aldrich).

7. Purified water.

8. Pipettes.

9. Microcentrifuge tubes.

10. Sterile Nalgene square $500 \mathrm{~mL}$ polycarbonate bottle (Thermo Scientific). 


\subsection{Adjuvant Formulation}

\subsection{Mouse Immunogenicity Testing}

2.7 Animal Challenge Studies
1. Delta inulin adjuvant suspended in bicarbonate buffer (Vaxine Pty Ltd).

2. CpG oligonucleotide powder (Oligo Factory, USA).

3. Water for injection (Baxter).

1. Female 6-8-week-old BALB/c mice weighing 18-20 g.

2. $0.5 \mathrm{~mL}$ Insulin syringes $(\mathrm{BD})$.

3. $5 \mathrm{~mL}$ Syringes.

4. $25 \mathrm{G} 5 / 8$ needles.

5. Animal lancet, $4 \mathrm{~mm}$ (Medipoint Inc., USA).

6. 96-Well ELISA plates (Greiner Bio-One).

7. 24-Well culture plates (Greiner Bio-One).

8. 0.1 M Sodium carbonate buffer, $\mathrm{pH}$ 9.6.

9. $1 \% \mathrm{BSA} / \mathrm{PBS}$.

10. Biotinylated anti-mouse IgG, IgG1, IgG2a, IgG2b, IgG3, or IgM antibodies (Abcam).

11. Streptavidin-HRP (BD Biosciences).

12. TMB substrate (KPL, USA).

13. $1 \mathrm{M}$ Phosphoric Acid.

14. Cell strainers, $70 \mu \mathrm{m}$ Nylon (Falcon).

15. RPMI complete medium with $10 \%$ heat-inactivated FBS (Invitrogen Life Technologies).

16. Red blood cell (RBC) lysis buffer (155 $\mathrm{mM} \mathrm{NH}_{4} \mathrm{Cl} ; 10 \mathrm{mM}$ $\mathrm{KHCO}_{3} ; 0.1 \mathrm{mM}$ EDTA, pH 7.3).

17. Carboxy-fluorescein diacetate succinimidyl ester (CFSE) (Invitrogen Life Technologies).

18. MultiScreen HTS, 96-well filtration plate (Merck Millipore).

19. Anti-mouse CD16/CD32 (BD Biosciences).

20. Anti-mouse CD4-APC (BD Biosciences).

21. Anti-mouse CD8a-PE-Cy7 (BD Biosciences).

22. Anti-mouse IFN- $\gamma$, IL-2, IL-4 antibody pairs (BD Biosciences).

23. LEAF anti-mouse IL-17A and biotin-anti-mouse IL-17A antibody (BioLegend, USA).

1. Female 4-8-week-old BALB/c mice weighing 18-20 g.

2. SARS-CoV virus strain Urbani (200300592), Centers for Disease Control and Prevention, Atlanta, GA, USA.

3. Vero 76 cell line (American Type Culture Collection, Manassas, VA, USA).

4. Hematoxylin and eosin stain. 
5. Rat monoclonal antibody (Clone MT-14.7) to eosinophil major basic protein MBP (Lee Laboratory, Mayo Clinic, Arizona).

6. DAB chromogen.

\section{Methods}

\subsection{Fermentation Harvest}

\subsection{UNO S/DEAE Column Chromatography}

1. Separate cells and culture supernatant by centrifugation at $5900 \times g$ at $2-8{ }^{\circ} \mathrm{C}$ for $15 \mathrm{~min}$.

2. Transfer culture supernatant to a sterile $50 \mathrm{~L}$ carboy.

3. After all culture supernatant is collected, filter through 0.22 $\mu \mathrm{m}$ filter into a second sterile $50 \mathrm{~L}$ carboy (see Note 1 ).

4. Store at $2-8{ }^{\circ} \mathrm{C}$.

1. Pack a BPG column with 1.9 L of UNO S resin (see Note 2).

2. Pack a BPG column with 1.5 L of DEAE Sepharose Fast Flow resin.

3. $\mathrm{pH}$ equilibrate the UNO S column with $0.5 \mathrm{M}$ Tris $\mathrm{pH} 7.4$ at a flow rate of $200-400 \mathrm{~mL} / \mathrm{min}$ until outflow $\mathrm{pH}$ is $7.0-$ 7.7. This step typically requires 3 column volumes of buffer ( see Note 3 ).

4. Continue equilibration of the UNO S column with $20 \mathrm{mM}$ Tris $\mathrm{pH} 7.4$ at a flow rate of $200-400 \mathrm{~mL} / \mathrm{min}$ until outflow is $\mathrm{pH} 7.2-7.5$ and conductivity is $\leq 500 \mathrm{mS}$. This step typically requires 5 column volumes.

5. $\mathrm{pH}$ equilibrate the DEAE column with $0.5 \mathrm{M}$ Tris $\mathrm{pH} 7.4$ at a flow rate of $200-400 \mathrm{~mL} / \mathrm{min}$ until outflow $\mathrm{pH}$ is $6.9-7.6$. This step typically requires 3 column volumes of buffer.

6. Continue equilibration of the DEAE column with $20 \mathrm{mM}$ Tris $\mathrm{pH} 7.4$ at a flow rate of $200-400 \mathrm{~mL} / \mathrm{min}$ until outflow is $\mathrm{pH}$ $7.0-7.5$ and conductivity is $\leq 500 \mathrm{mS}$. This step typically requires 5 column volumes.

7. Connect the DEAE column to the outflow of the UNO $S$ column.

8. Equilibrate the linked UNO $S$ and DEAE columns with 20 $\mathrm{mM}$ Tris $\mathrm{pH} 74$ at a flow rate of $200-400 \mathrm{~mL} / \mathrm{min}$ until outflow is pH 6.9-7.6 and conductivity is $\leq 500 \mathrm{mS}$.

9. Apply the culture supernatant from Subheading 2.1 to the linked UNO S/DEAE columns at a flow rate of not more than $300 \mathrm{~mL} / \mathrm{min}$ ( see Note 4 ).

10. Begin collecting the flow through from the linked columns into a $50 \mathrm{~L}$ carboy when the UV trace begins to rise.

11. Wash the linked columns with $20 \mathrm{mM}$ Tris pH 7.4 and collect the wash in the carboy with the column flow through. 
3.3 Lentil Lectin Capture Chromatography
12. Collect $\leq 10 \mathrm{~L}$ of wash, and stop collection of the wash when the UV trace returns to baseline.

13. Proceed to lentil lectin capture chromatography.

1. Pack XK-50 column with $250 \mathrm{~mL}$ of lentil lectin sepharose (see Note 2).

2. Equilibrate lentil lectin column with $20 \mathrm{mM}$ Tris $\mathrm{pH} 7.4$ at a flow rate of $50-100 \mathrm{~mL} / \mathrm{min}$ using 10 column volumes of buffer. $\mathrm{pH}$ should be 7.2-7.5.

3. Load UNO $S / D E A E$ flow through to the lentil lectin column at a flow rate of 50-100 mL/min (see Note 5).

4. Wash column with $20 \mathrm{mM}$ Tris $\mathrm{pH} 7.4$ at a flow rate of 50-100 $\mathrm{mL} / \mathrm{min}$ for 5 column volumes or until UV trace returns to baseline.

5. Collect fractions in sterile Nalgene square $250 \mathrm{~mL}$ polycarbonate bottles.

6 . Elute with 2 column volumes of $50 \mathrm{mM} \mathrm{N}$-methyl- $\alpha$-Dmannopyranoside and $20 \mathrm{mM}$ Tris $\mathrm{pH} 7.4$ at a flow rate of 50-100 mL/min. Collect two $250 \mathrm{~mL}$ fractions.

7. Elute with 2 column volumes of $100 \mathrm{mM} \mathrm{N}$-methyl- $\alpha$-Dmannopyranoside and $20 \mathrm{mM}$ Tris $\mathrm{pH} 7.4$ at a flow rate of 50-100 mL/min. Collect two $250 \mathrm{~mL}$ fractions.

8. Elute with 2 column volumes of $200 \mathrm{mM} \mathrm{N}$-methyl- $\alpha-\mathrm{D}$ mannopyranoside and $20 \mathrm{mM}$ Tris $\mathrm{pH} 7.4$ at a flow rate of $50-100 \mathrm{~mL} / \mathrm{min}$. Collect two $250 \mathrm{~mL}$ fractions.

9. Elute with 5 column volumes of $500 \mathrm{mM} \mathrm{N}$-methyl- $\alpha$-Dmannopyranoside and $20 \mathrm{mM}$ Tris $\mathrm{pH} 7.4$ at a flow rate of $50-100 \mathrm{~mL} / \mathrm{min}$. Collect $250 \mathrm{~mL}$ fractions until UV trace is flat and stable.

10. Store fractions at $2-8^{\circ} \mathrm{C}$.

11. Analyze all fractions by SDS-PAGE and Western blot to determine which fractions contain SARS S $\Delta$ TM protein.

12. Pool fractions containing detectable SARS S $\Delta$ TM protein.

\subsection{Concentration, Ultrafiltration, and $0.22 \mu \mathrm{m}$ Filtration}

1. Assemble Sartocon Slice 200 bench top ultrafiltration system with a $0.1 \mathrm{~m}^{2} 50 \mathrm{kDa}$ molecular weight cutoff Sartocon Slice cassette according to the manufacturer's instructions.

2. Attach a process tank according to the manufacturer's instructions.

3. Fill process tank with water for injection (WFI).

4. Close permeate valve and circulate WFI through the system at $200 \mathrm{~mL} / \mathrm{min}$ for 3-4 $\mathrm{min}$.

5. Open permeate valve.

6. Increase circulation rate to $600-800 \mathrm{~mL} / \mathrm{min}$. 
7. Adjust retentate valve to obtain a transmembrane pressure (TMP) of 8.0-17.0 psi.

8. Continue rinsing for $5-10 \mathrm{~min}$.

9. Repeat steps $\mathbf{3}-\mathbf{8}$ using diafiltration buffer $(150 \mathrm{mM} \mathrm{NaCl}$, $2.5 \mathrm{mM} \mathrm{NaPO}_{4} \mathrm{pH}$ 6.8-7.2 in WFI).

10. Fill process tank with pooled SARS $S \Delta \mathrm{TM}$ protein.

11. Retentate line should be connected to process tank, and valve should be open.

12. Allow $S \Delta T M$ to recirculate through the system at a flow rate of $\leq 200 \mathrm{~mL} / \mathrm{min}$ for $3-4 \mathrm{~min}$.

13. Increase recirculation flow rate to $600-800 \mathrm{~mL} / \mathrm{min}$.

14. Ensure a TMP of 13.0-17.0 psi.

15. Monitor volume in process tank.

16. Stop concentration when volume in process tank is approximately $400 \mathrm{~mL}$. This is the initial concentration retentate.

17. Set up a $2 \mathrm{~L}$ vessel to siphon into process tank.

18. Fill container with $2 \mathrm{~L}$ of diafiltration buffer $(150 \mathrm{mM} \mathrm{NaCl}$, $2.5 \mathrm{mM} \mathrm{NaPO}_{4} \mathrm{pH}$ 6.8-7.2 in WFI).

19. Retentate valve should be open.

20. Start pump and circulate at a flow rate of $\leq 200 \mathrm{~mL} / \mathrm{min}$ for 3-4 min.

21 . Increase flow rate to $600-800 \mathrm{~mL} / \mathrm{min}$.

22. Adjust retentate valve to maintain a TMP of 13.0-17.0 psi.

23. Monitor volume of diafiltration buffer in vessel.

24. Continue until a total volume of diafiltration buffer equal to 10 times the volume of initial concentration retentate has been used.

25 . Volume in process tank should be approximately equal to initial concentration retentate volume. This is the diafiltration retentate.

26. Process the diafiltration retentate through a $0.22 \mu \mathrm{m}$ filter into a sterile Nalgene polycarbonate bottle. This is the S $\Delta \mathrm{TM}$ bulk drug substance.

27. Remove aliquots for testing.

28. Store bulk drug substance at $-20^{\circ} \mathrm{C}$.

3.5 Antigen Release Testing

3.6 Vaccine Adjuvant Formulation
1. Testing and acceptance criteria for SARS $S \Delta T M$ are listed in Table 1.

1. Advax ${ }^{\mathrm{TM}}$ is a preservative-free sterile suspension of delta inulin microparticles at $50 \mathrm{mg} / \mathrm{mL}$ in a bicarbonate buffer, which when combined with vaccine antigen enhances both Thl and Th2 immunity in a balanced fashion. 
Table 1

SARS S $\Delta$ TM analytical tests and acceptance criteria

\begin{tabular}{lll}
\hline Parameter & Method & Acceptance criterion \\
\hline Identity & SDS-PAGE/Western blot & $\begin{array}{l}\text { Detection of approx. } 150 \mathrm{kDa} \text { protein with SARS } \\
\text { S antiserum }\end{array}$ \\
\hline DNA content & PicoGreen & $\leq 15 \mathrm{ng} / \mathrm{dose}$ \\
\hline $\mathrm{pH}$ & $\mathrm{USP}<79 \mathrm{l}>$ & $7.0 \pm 0.4$ \\
\hline Osmolality & USP $<785>$ & $\leq 330 \mathrm{mOsm} / \mathrm{hg}$ \\
\hline Bacterial endotoxin & USP $<85>$ & $<10 \mathrm{EU} /$ dose \\
\hline Purity & SDS-PAGE/Western blot & $\geq 90 \%$ \\
\hline Lentil lectin content & SDS-PAGE/Western blot & $<10 \mathrm{ng}$ lentil lectin/ $\mu \mathrm{g}$ SARS S $\Delta \mathrm{TM}$ \\
\hline Microbial limits & USP $<6 \mathrm{l}>$ & $<10 \mathrm{CFU} / \mathrm{mL}$ \\
\hline Total protein & Bicinchoninic acid assay & Perform and report \\
\hline Potency & ELISA & $\geq 60 \%$ of total protein content \\
\hline
\end{tabular}

3.7 Animal Immunogenicity Testing
2. To further enhance Thl and reduce Th2 immune bias, $10 \mu \mathrm{g}$ CpG oligonucleotide per $1 \mathrm{mg}$ delta inulin is added to the Advax $^{\mathrm{TM}}$ adjuvant, as a simple admixture.

3. Advax ${ }^{\mathrm{TM}}$ adjuvant formulations are administered to mice at a standardized dose of $1 \mathrm{mg}$ delta inulin per mouse, irrespective of the antigen dose.

4. Advax ${ }^{\mathrm{TM}}$ adjuvant is formulated with $S \Delta \mathrm{TM}$ bulk drug substance in a laminar flow hood by aseptic simple admixture of the Advax ${ }^{\mathrm{TM}}$ suspension with the $S \Delta \mathrm{TM}$ bulk drug substance and drawing up the combined milky white suspension into a $0.5 \mathrm{~mL}$ insulin syringe immediately prior to immunization.

1. Vaccine immunogenicity studies can be conveniently performed on adult female BALB/c mice at 6-8 weeks of age but can also be performed on other strains such as C57BL/6 (see Note 6).

2. Mice are immunized twice 3 weeks apart by an intramuscular injection into the thigh, in order to mimic the most common route of human vaccine administration. The maximum volume that can be injected into an adult mouse thigh muscle is $50 \mu \mathrm{l}$. If the vaccine cannot be reduced to this volume, then providing the vaccine is not reactogenic and then larger vaccine volumes can be administered by injection of $50 \mu$ l amounts into multiple legs.

3. Starting at 1 week post-immunization, at intervals of $1-4$ weeks mice are bled using cheek vein bleeding using a lancet in order to obtain $\sim 25-50 \mu \mathrm{l}$ of blood from which serum is 
obtained by centrifugation and then stored at $-20{ }^{\circ} \mathrm{C}$ for later use in antibody assays.

4. SARS-specific antibodies are conveniently determined in mouse serum by ELISA. $S \Delta$ TM protein is absorbed to ELISA plates in $0.1 \mathrm{M}$ sodium carbonate buffer, $\mathrm{pH} 9.6$ and incubated overnight at $4{ }^{\circ} \mathrm{C}$. After blocking with $1 \% \mathrm{BSA} / \mathrm{PBS}$ for $1 \mathrm{~h}$, serum samples diluted in $1 \% \mathrm{BSA} / \mathrm{PBS}$ are incubated for $2 \mathrm{~h}$ at room temperature (RT) and then washed. Subsequently, $100 \mu$ biotinylated anti-mouse IgG, IgGl, IgG2a, IgG2b, IgG3, or IgM antibodies (Abcam) plus streptavidin-HRP (BD Biosciences) are added and incubated for $\mathrm{l} \mathrm{h}$ at RT. After washing, wells are incubated with $100 \mu \mathrm{l}$ of TMB substrate for $10 \mathrm{~min}$ and then stopped by $1 \mathrm{M}$ phosphoric acid. The optical density is measured at $450 \mathrm{~nm}(\mathrm{OD} 450 \mathrm{~nm})$ with a VersaMax ELISA microplate reader (Molecular Devices, CA, USA) and analyzed using SoftMax Pro Software.

5. At the termination of immunogenicity studies, mice are killed by cervical dislocation and bones and spleens are collected to enable measurement of SARS-specific memory $\mathrm{T}$ and $\mathrm{B}$ cells. Bone marrow is isolated from femurs by flushing with $3 \%$ FBS/PBS. Splenocytes are released by pressing against a cell strainer with a rubber syringe plunger and RBCs are removed by osmotic shock. Cells are washed with $3 \% \mathrm{FBS} / \mathrm{PBS}$ and then resuspended in RPMI complete medium with $10 \%$ heatinactivated FBS.

6. For $\mathrm{T}$ cell proliferation assays, splenocytes are labeled with 5 $\mu \mathrm{M}$ CFSE (Invitrogen Life Technologies) for $8 \mathrm{~min}$ at RT. CFSE starts to react when exposed to aqueous solutions. It is, therefore, important to avoid dilution of CFSE until immediately before cell labeling.

7. Labeled cells are cultured in 24-well plates at $10^{6}$ cells $/ \mathrm{mL} /$ well with or without $S \Delta$ TM protein $1 \mu \mathrm{g} / \mathrm{mL}$. After 5 -day incubation at $37{ }^{\circ} \mathrm{C}$ and $5 \% \mathrm{CO}_{2}$, cells are washed with $0.1 \%$ $\mathrm{BSA} / \mathrm{PBS}$, treated with anti-mouse CD16/CD32 (BD Biosciences) for $5 \mathrm{~min}$ at $4{ }^{\circ} \mathrm{C}$ and then stained with antimouse CD4-APC and anti-mouse CD8a-PE-Cy7 (BD) for $30 \mathrm{~min}$ at $4{ }^{\circ} \mathrm{C}$. Cells are washed with $0.1 \% \mathrm{BSA} / \mathrm{PBS}$ and then analyzed by FACS (FACSCanto II, BD Biosciences) with FACSDiva software. For each lymphocyte subset, proliferation is expressed as the percentage of divided cells (CFSE low) compared to undivided cells (CFSE high). Dot plots representing analysis of $10^{5}$ cells are generated by FlowJo software. It is important to have CFSE-labeled, unstimulated cells as a nondividing cell control.

8. The frequency of antigen-specific antibody- or cytokinesecreting cells is analyzed using biotinylated anti-mouse IgG, 
IgG1, IgG2a, or IgM antibodies (Abcam) or anti-mouse IFN$\gamma$, IL-2, and IL-4 antibody pairs (BD) or LEAF anti-mouse IL-17A and biotin-anti-mouse IL-17A antibody (BioLegend, USA) with streptavidin-HRP (BD Biosciences), according to the manufacturer's instruction. Briefly, single-cell suspensions are prepared from bone marrow and spleens of mice at indicated time points, plated at $2 \times 10^{5}$ cells/well in 96-well filtration plates pre-coated with $S \Delta T M$ protein (for antibody detection) or anti-mouse cytokine $\mathrm{mAb}$ (for cytokine detection) overnight at $4{ }^{\circ} \mathrm{C}$, and then blocked with RPMI/10\% FBS. For cytokine assays, the cells are incubated with $S \Delta T M$ protein $(10 \mu \mathrm{g} / \mathrm{mL})$ at $37{ }^{\circ} \mathrm{C}$ and $5 \% \mathrm{CO}_{2}$ for 2 days. Wells are washed and incubated with biotinylated anti-mouse Ig or anti-mouse cytokine $\mathrm{mAb}$ at RT for $2 \mathrm{~h}$, and washed, and then streptavidin-HRP is added for $\mathrm{l} \mathrm{h}$ before washing and addition of AEC substrate solutions (BD Biosciences). Spots are counted by ImmunoSpot S6 ELISPOT analyzer (CTL, USA) and analyzed using ImmunoSpot Software. Spots in negative control wells are subtracted from the number of spots in $S$ protein wells and the results are expressed as antibody-secreting cells (ASC) per $10^{6} \mathrm{BM}$ cells or spots per $10^{6}$ splenocytes.

9. For statistical analysis, group comparisons for antibody and ELISPOT tests are done by Mann-Whitney test.

3.8 SARS CoV Mouse Challenge Studies
1. Female 4-6-week-old BALB/c mice weighing 18-20 g are obtained from Charles River Laboratories (Wilmington, MA), maintained on Wayne Lab Blox, and fed with standard mouse chow and tap water ad libitum (see Note 6).

2. To generate a mouse-adapted SARS-CoV, the SARS-CoV strain Urbani (200300592) was obtained from Centers for Disease Control and Prevention (CDC, Atlanta, GA, USA). This strain was propagated and titrated in Vero 76 cells obtained from American Type Culture Collection (ATCC, Manassas, VA), and grown in minimal essential medium (MEM) supplemented with $10 \%$ heat-inactivated fetal bovine serum (FBS, Thermo Fisher Scientific Co., Logan, UT). For in vitro antiviral assays, the serum was reduced to $2 \% \mathrm{FBS}$ and gentamicin was added to the medium up to a final concentration of $50 \mu \mathrm{g} / \mathrm{mL}$. BALB $/ \mathrm{c}$ mice were infected with the Urbani strain. Three or five days after infection, the lungs were removed and homogenized and then used to reinfect a subsequent group of mice. This infection step was continued 25 times through BALB/c mice lungs. The virus was then plaquepurified three times and yielded a virus causing severe lung disease and mortality in infected mice. The virus was verified as SARS-CoV by enzyme-linked immunosorbent assay (ELISA) and polymerase chain reaction (PCR). All experiments involving 
infectious SARS-CoV viruses need to be conducted in an approved biosafety level 3+ laboratory.

3. At days 3 and 6 post-virus challenge, five mice from each immunized and control group are sacrificed and the lungs harvested for gross pathology (lung score), lung weights, lung virus titers, and measurement of anti-SARS IgG in lung homogenate.

4. For lung scoring, samples from each mouse lung lobe are weighed and placed in a petri dish. Lungs are scored based on surface appearance of lungs. Lungs are then assigned a score ranging from 0 to 4 , with 0 indicating that the lungs looked normal and 4 denoting that the entire surface area of the lungs was inflamed and exhibited plum-colored lung discoloration. Significant differences in lung scores are determined by Kruskal-Wallis test followed by Dunn's pairwise comparison post tests. Analysis of variance (ANOVA) is used to determine significant differences in lung weights. Pairwise comparisons are made by Newman-Keuls posttests.

5. Lung virus titers are analyzed from mice sacrificed on days 3 and 6 post-virus exposure. A lobe from each mouse lung is homogenized in MEM supplemented with $10 \%$ FBS and the tissue fragments are allowed to settle. The varying dilutions of the supernatant fluids are assayed in triplicate for infectious virus in Vero 76 cells by cytopathic effect (CPE) assay. The titers ( $50 \%$ tissue culture infectious dose, CCID50 values) are calculated using the Reed-Muench method. Significant differences are detected by ANOVA. Pairwise comparisons are made by Newman-Keuls posttests.

6. For SARS-CoV neutralizing antibody assay sera are harvested by submandibular bleeding from surviving mice at days 7 and 14 after virus challenge. $7 \mu \mathrm{l}$ aliquot of each serum sample is added to approximately $63 \mu \mathrm{l}$ of MEM, mixed, and then serially diluted by $1 / 2$ to achieve $1 / 40$ to $1 / 8192$ dilutions in 96 -well plates. Virus stock is diluted in MEM to approximately 200 CCID50 per $60 \mu \mathrm{l}$. Next $60 \mu \mathrm{l}$ of virus is added to each well, and the plates are vibrated for approximately $1 \mathrm{~min}$, and then incubated for $1 \mathrm{~h}$ at $37^{\circ} \mathrm{C}$ for neutralization. $100 \mu \mathrm{l}$ of the liquid from each well is then transferred to 96-well plates containing sub-confluent monolayers of Vero 76 cells, and $100 \mu \mathrm{l}$ of MEM $+4 \%$ FBS added to each well. Plates are sealed with tape, incubated for 5 days at $37{ }^{\circ} \mathrm{C}$ with $5 \% \mathrm{CO}_{2}$, and scored for the presence or absence of virus CPE. Uninfected wells serve as a negative cell control, and a serum sample with known anti-SARS antibody as a positive control. Results are reported as the inverse of the greatest dilution where virus CPE is not detected.

7. To assess for effects of vaccines on lung eosinophilic immunopathology, immunized and vehicle-treated mice are sacrificed at days 3 and 6 post-virus challenge, and lungs removed. 
Formalin-fixed lungs are mounted in paraffin blocks. Paraffinembedded lung sections are stained with hematoxylin and eosin (H\&E) and a rat monoclonal antibody (Clone MT-14.7) to eosinophil major basic protein MBP (Lee Laboratory, Mayo Clinic, Arizona) following a standard IHC procedure. DAB chromogen identifies eosinophils as brown-stained cells. Eosinophil infiltration is scored without knowing animal identity using H\&E-stained slides. An overall infiltration score, $0-3$, is assigned to each section according to the amounts of eosinophils in the parenchyma and their distributions through the lung. Score $0=$ no to a few eosinophils; score $\mathrm{l}=$ mild eosinophil infiltration; score $2=$ moderate infiltration; score $3=$ severe infiltration. For confirmation, immunohistochemistry to the eosinophil major basic protein is performed in sections with the highest score of each treatment group.

8. The remainder of the mice are followed for 2 weeks postchallenge to assess survival. Survival analysis is done using the Kaplan-Meier method and a Logrank test. If that analysis reveals statistically significant differences among the treatment groups, pairwise comparison of survivor curves is analyzed by the Mantel-Cox Logrank test, and the relative significance adjusted to a Bonferroni-corrected significance threshold for the number of treatment comparisons done. All group comparisons of virus titers are done using analysis of variance to determine experimental significance followed by NewmanKeuls pairwise comparison tests.

1. Because the $S \Delta T M$ protein the culture supernatant is in a rich culture medium, all practical precautions should be taken to prevent microbial growth. All containers should be sterile, buffers should be $0.22 \mu \mathrm{m}$ filtered, columns and chromatography systems should be thoroughly sanitized after use, and process intermediates should be processed immediately or stored at $2-8{ }^{\circ} \mathrm{C}$.

2. Columns should be packed ahead of time and stored according to the resin manufacturer's recommendations.

3. Columns may be equilibrated during harvest of the culture.

4. Culture supernatant containing $S \Delta T M$ may be loaded onto the linked UNO S/DEAE columns immediately after harvest.

5. The lentil lectin sepharose column may be loaded immediately after completion of the UNO S/DEAE step, and the load may be run overnight.

6. BALB/c mice are typically used for vaccine studies as they have a Th2 immune bias and hence are good at making antibody responses, whereas C57BL/6 mice have a Thl bias. 


\section{References}

1. Nicholls J, Dong XP, Jiang G et al (2003) SARS: clinical virology and pathogenesis. Respirology 8 Suppl:S6-S8

2. Berger A, Drosten C, Doerr HW et al (2004) Severe acute respiratory syndrome (SARS) paradigm of an emerging viral infection. J Clin Virol 29:13-22

3. Assiri A, McGeer A, Perl TM et al (2013) Hospital outbreak of Middle East respiratory syndrome coronavirus. N Engl J Med 369:407-416

4. Marra MA, Jones SJ, Astell CR et al (2003) The Genome sequence of the SARS-associated coronavirus. Science 300:1399-1404

5. Darnell ME, Plant EP, Watanabe H et al (2007) Severe acute respiratory syndrome coronavirus infection in vaccinated ferrets. J Infect Dis 196:1329-1338

6. Bolles M, Deming D, Long K et al (2011) A double-inactivated severe acute respiratory syndrome coronavirus vaccine provides incomplete protection in mice and induces increased eosinophilic proinflammatory pulmonary response upon challenge. J Virol 85: 12201-12215

7. See RH, Zakhartchouk AN, Petric $M$ et al (2006) Comparative evaluation of two severe acute respiratory syndrome (SARS) vaccine candidates in mice challenged with SARS coronavirus. J Gen Virol 87:641-650

8. Yasui F, Kai C, Kitabatake M et al (2008) Prior immunization with severe acute respiratory syndrome (SARS)-associated coronavirus (SARS-CoV) nucleocapsid protein causes severe pneumonia in mice infected with SARSCoV. J Immunol 181:6337-6348

9. Tseng CT, Sbrana E, Iwata-Yoshikawa $\mathrm{N}$ et al (2012) Immunization with SARS coronavirus vaccines leads to pulmonary immunopathology on challenge with the SARS virus. PLoS One 7, e35421

10. Clay C, Donart N, Fomukong N et al (2012) Primary severe acute respiratory syndrome coronavirus infection limits replication but not lung inflammation upon homologous rechallenge. J Virol 86:4234-4244

11. Roper RL, Rehm KE (2009) SARS vaccines: where are we? Expert Rev Vaccines 8:887-898

12. Li W, Moore MJ, Vasilieva $\mathrm{N}$ et al (2003) Angiotensin-converting enzyme 2 is a functional receptor for the SARS coronavirus. Nature 426:450-454

13. Jeffers SA, Tusell SM, Gillim-Ross L et al (2004) CD209L (L-SIGN) is a receptor for severe acute respiratory syndrome coronavirus. Proc Natl Acad Sci U S A 101:15748-15753
14. He Y, Zhou Y, Wu H et al (2004) Identification of immunodominant sites on the spike protein of severe acute respiratory syndrome (SARS) coronavirus: implication for developing SARS diagnostics and vaccines. J Immunol 173: $4050-4057$

15. He Y, Lu H, Siddiqui P et al (2005) Receptorbinding domain of severe acute respiratory syndrome coronavirus spike protein contains multiple conformation-dependent epitopes that induce highly potent neutralizing antibodies. J Immunol 174:4908-4915

16. Huang J, Cao Y, Du J et al (2007) Priming with SARS CoV S DNA and boosting with SARS CoV $S$ epitopes specific for CD4+ and CD8+ $\mathrm{T}$ cells promote cellular immune responses. Vaccine 25:6981-6991

17. Zhou Z, Post P, Chubet R et al (2006) A recombinant baculovirus-expressed $\mathrm{S}$ glycoprotein vaccine elicits high titers of SARSassociated coronavirus (SARS-CoV) neutralizing antibodies in mice. Vaccine 24: 3624-3631

18. Openshaw PJ, Culley FJ, Olszewska W (2001) Immunopathogenesis of vaccine-enhanced RSV disease. Vaccine 20 Suppl 1:S27-S31

19. Petrovsky N, Aguilar JC (2004) Vaccine adjuvants: current state and future trends. Immunol Cell Biol 82:488-496

20. Cooper PD, Barclay TG, Ginic-Markovic M et al (2013) The polysaccharide inulin is characterized by an extensive series of periodic isoforms with varying biological actions. Glycobiology 23:1 164-1174

21. Cooper PD, Petrovsky N (2011) Delta inulin: a novel, immunologically active, stable packing structure comprising beta-D-[2 $\left.\begin{array}{lll}2 & -> & 1\end{array}\right]$ poly(fructo-furanosyl) alpha-D-glucose polymers. Glycobiology 21:595-606

22. Honda-Okubo Y, Saade F, Petrovsky N (2012) Advax, a polysaccharide adjuvant derived from delta inulin, provides improved influenza vaccine protection through broad-based enhancement of adaptive immune responses. Vaccine 30:5373-5381

23. Lobigs M, Pavy M, Hall RA et al (2010) An inactivated Vero cell-grown Japanese encephalitis vaccine formulated with Advax, a novel inulin-based adjuvant, induces protective neutralizing antibody against homologous and heterologous flaviviruses. J Gen Virol 91: 1407-1417

24. Feinen B, Petrovsky N, Verma A et al (2014) Advax-adjuvanted recombinant protective antigen provides protection against inhalational anthrax that is further enhanced by addi- 
tion of murabutide adjuvant. Clin Vaccine Immunol 21:580-586

25. Honda-Okubo Y, Kolpe A, Li L et al (2014) A single immunization with inactivated $\mathrm{HINl}$ influenza vaccine formulated with delta inulin adjuvant (Advax) overcomes pregnancyassociated immune suppression and enhances passive neonatal protection. Vaccine 32:4651-4659

26. Larena M, Prow NA, Hall RA et al (2013) JE-ADVAX vaccine protection against Japanese encephalitis virus mediated by memory B cells in the absence of CD8+ $\mathrm{T}$ cells and preexposure neutralizing antibody. J Virol 87:4395-4402

27. Layton RC, Petrovsky N, Gigliotti AP et al (2011) Delta inulin polysaccharide adjuvant enhances the ability of split-virion $\mathrm{H} 5 \mathrm{Nl}$ vaccine to protect against lethal challenge in ferrets. Vaccine 29:6242-6251

28. Petrovsky N, Larena $M$, Siddharthan V et al (2013) An inactivated cell culture Japanese encephalitis vaccine (JE-ADVAX) formulated with delta inulin adjuvant provides robust heterologous protection against West Nile encephalitis via cross-protective memory $\mathrm{B}$ cells and neutralizing antibody. J Virol 87:10324-10333

29. Saade F, Honda-Okubo Y, Trec S et al (2013) A novel hepatitis $B$ vaccine containing Advax, a polysaccharide adjuvant derived from delta inulin, induces robust humoral and cellular immunity with minimal reactogenicity in preclinical testing. Vaccine 31:1999-2007

30. Cristillo AD, Ferrari MG, Hudacik L et al (2011) Induction of mucosal and systemic antibody and T-cell responses following primeboost immunization with novel adjuvanted human immunodeficiency virus-1-vaccine formulations. J Gen Virol 92:128-140

31. Gordon D, Kelley P, Heinzel S et al (2014) Immunogenicity and safety of Advax, a novel polysaccharide adjuvant based on delta inulin, when formulated with hepatitis B surface antigen: a randomized controlled Phase 1 study. Vaccine 32(48):6469-6477

32. Gordon DL, Sajkov D, Woodman RJ et al (2012) Randomized clinical trial of immunogenicity and safety of a recombinant $\mathrm{HlNl} / 2009$ pandemic influenza vaccine containing Advax polysaccharide adjuvant. Vaccine 30:5407-5416

33. Honda-Okubo Y, Barnard D, Ong CH et al (2015) Severe acute respiratory syndromeassociated coronavirus vaccines formulated with delta inulin adjuvants provide enhanced protection while ameliorating lung eosinophilic immunopathology. J Virol 89:2995-3007 